Pak. j. sci. ind. res. Ser. A: phys. sci. 201558 (2) 111-116

\title{
Evaluation of Pesticide Residues in Drinking Water in Different Areas of Khyber Pakhtunkhwa, Pakistan
}

\author{
Muhammad Nasimullah Qureshi ${ }^{a *}$ and Inayat Ur Rahman ${ }^{\mathrm{b}}$ \\ ${ }^{a}$ Department of Chemistry, Abdul Wali Khan University, Mardan, Pakistan \\ ${ }^{b}$ Medicinal Botanic Centre, PCSIR Laboratories Complex, Peshawar-25100, Pakistan
}

(received February 4, 2014; revised April 22, 2014; accepted May 6, 2014)

\begin{abstract}
Flood in 2010 severely effected different areas of Khyber Pakhtunkhwa, Sindh, lower Punjab as well as some parts of Balochistan, Pakistan. After the flood, samples of drinking water were collected from the affected areas i.e. Akora Khattak and Buner, Khyber Pakhtunkhwa and pesticides residues were determined quantitatively in these samples employing GC-MS technique. Among the samples collected from Akora Khattak, chlorpyrifos was found in high amounts i.e. $0.040 \mathrm{ppm}$, in sample no. 6 while methamidophos and methiocarb were found in appreciable quantities i.e. $0.026 \mathrm{ppm}$ and $0.038 \mathrm{ppm}$, respectively, in sample no. 4. Methamidophos and methiocarb were found in appreciable amounts i.e. $0.039 \mathrm{ppm}$ and $0.034 \mathrm{ppm}$, respectively, in sample no. 17 among the samples obtained from Buner. Concentrations were found at the level below $0.01 \mathrm{ppm}$ in most of the pesticides under study. From the results it appears that drinking water sources in the area under study have been contaminated with pesticides which is a health hazard and may be a source of various diseases in these areas.
\end{abstract}

Keywords. flood hit area, drinking water, pesticides, GC-MS technique

\section{Introduction}

In Pakistan, in the month of July 2010, water rose up of the level after the heavy monsoon rain fall and came out of brim from the rivers in the form of flood. This flood hit different areas of Pakistan, severely affecting the Khyber Pakhtunkhwa, Sindh, lower Punjab as well as some parts of Baluchistan. About one fifth of Pakistan's total land area was underwater due to the flooding. More than that two thousand people lost their lives and about a million homes perished. As per reports of the United Nations, over 20 million people were suffering and homeless with over 160,000 square kilometers area affected as a result of the floods, exceeding the combined total of the affecters of 2004, due to Indian Ocean Tsunami, the 2005 Kashmir earthquake and the 2010 Haiti earthquake. However, the death toll in each of those three disasters was much higher than the number of people killed so far in these floods (Abid et al., 2010).

Among the provinces of the country, Khyber Pakhtunkhwa was badly damaged, affected primarily the basic necessities of life such as food, shelter and clothing. Unhygienic and contaminated drinking water with pathogenic microorganisms and chemicals like pesticides and herbicides was the most alarming after effects of the flood. The surface

*Author for correspondence; E-mail: mnasimuq@yahoo.com water drained the pesticides and herbicides used in agricultural activities into the drinking water resources, making it highly contaminated and harmful for the human consumption.

Use of pesticides to control the insectivorous and herbaceous pests in order to produce good quality and quantity of crops is a fundamental contribution to the Green Revolution. On the other hand some have threatened the long-term survival of major ecosystems by disruption of predator-prey relationships and loss of biodiversity. Pesticides can have significant human health consequences (Hernández et al., 2013; Hayat et al., 2010; Moon et al., 2009) like neurotoxicity (Androutsopoulos et al., 2013; Zaganas et al., 2013; Kanavouras et al., 2011; Bassil et al., 2007; Karalliedde and Senanayake, 1999; Brown et al., 1989) and can produce gastrointestinal, cardiological, dermatological, respiratory, genitor-urinary and musculoskeletal problems (Kesavachandran et al., 2009; Soomro et al., 2008; Palis et al., 2006; Salameh et al., 2006; Vial et al., 1996; Hueser, 1992). Studies have shown that these chemicals are injurious to immune and endocrine systems (Abhilash and Singh, 2009; Soomro et al., 2008; Luster and Rosenthal, 1993; Chambers, 1992; Arlien-Soberg, 1992).

Contamination of drinking water after flood is a serious environmental issue and a health threat. Flood water can 
be contaminated with a variety of substances including pathogenic microorganisms, automotive fluids, animal wastes, fertilisers, chemicals like pesticides etc. Surface water is drained into the ground water carrying these contaminants. Contamination of drinking water with pesticides cause a number of health problems. Therefore, determination of pesticide residues in drinking water sources is important in order to take appropriate measures for the provision of safe drinking water to public and protection of public health.

Liquid-liquid extraction, which is the most common technique of extracting organic compounds from aqueous phase, is carried out by mixing the aqueous phase with other immiscible organic solvents like ethyl acetate, dichloromethane and hexane. A variety of analytical techniques are used for the analysis of pesticides including chromatographic techniques like GC and HPLC coupled to various detection systems. GC-MS is the method of choice which is a robust and routinely employed for pesticides analyses. This paper presents the results of pesticides residues determination in drinking water samples from different affected areas of Khyber Pakhtunkhwa.

\section{Materials and Methods}

Chemicals and reagents. Ethyl acetate (GC grade) and dichloromethane (GC grade) were purchased from Fischer Scientific (Leicestershire, UK). Sodium sulphate anhydrous (analytical grade), potassium dihydrogen phosphate, $\mathrm{HCl}$ and sodium chloride (analytical grade) were obtained from Merck (Darmstadt, Germany). GC grade pesticide standards acetamiprid, acetochlor, atrazine, cypermethrin, dichlorvos, difenoconazole, and pyridaben were purchased from AccuStandard New Haven, CT, USA. Aldicarb (99.9\%), alpha endosulfan (99.6\%), betaendosulfan (99.9\%), chlorpyrifos (99.2\%), cyhalothrin (99.7\%), fenvalerate (99.8\%), methamido-phos (98.4\%) and popachlor (99.5\%) were procured from Sigma-Aldrich GmbH, Seelze, Germany. Carbofuran (98.5\%), dieldrin (98.3\%), methiocarb (98.5\%), o, p'-DDD (99.6\%), o,p'DDT (99.5\%) and p,p'-DDE (98.5\%) were obtained from Dr. Ehrenstorfer GmbH Ausburg, Germany. Helium gas (99.9999\%) was procured from Pak Gas (United Arab Emirates). Double distilled water was used through out the experimental work.

Preparation of pesticide standard mixture. Stock solutions of the individual pesticides under study were prepared in methanol. From each solution appropriate volume was mixed together in a vial. $2 \mu \mathrm{L}$ of the standard mixture was injected into the GC column using auto injection system of GC-MS.

Samples collection. Total of 25 samples from drinking water sources (well water) were collected on random basis from Akora Khattak and Buner district in clean and sterilised bottles and numbers were alloted to these samples. Among these: 8 samples were collected from Akora Khattak and 17 samples from Buner. Samples were properly preserved until their use for experimental work. The pesticides selected for the study were those which are most commonly sprayed in these areas as insecticides and herbicides, and are easily available in the form of standards. The data of the most commonly used pesticides in the area has been taken from the Department of Agriculture Training Institute Peshawar, Khyber Pakhtunkhwa. For this study, total of 23 pesticides were selected as shown in Table 1 .

Extraction of pesticides and preparation of samples. The procedure adopted was according to the official methods of analysis of AOAC International with some modifications (AOAC, 2002). Water sample (1 L) was adjusted to $\mathrm{pH}$ by adding phosphate buffer ( $\mathrm{pH} 7) . \mathrm{NaCl}$ $(100 \mathrm{~g})$ was dissolved in this solution followed by the addition of $300 \mathrm{~mL}$ of ethyl acetate. The mixture was

Table 1. GC-MS data of pesticides standard mixture

\begin{tabular}{|c|c|c|c|c|}
\hline $\begin{array}{l}\text { Sample } \\
\text { no. }\end{array}$ & Pesticides name & $\begin{array}{l}\text { R. Time } \\
(\min )\end{array}$ & $\begin{array}{l}\text { Conc. } \\
\text { (ppm) }\end{array}$ & $\begin{array}{l}\text { Quantifying ion } \\
\text { (base peak) } \\
\text { (m/z value) }\end{array}$ \\
\hline 1 & Aldicarb & 3.86 & 38.591 & 68 \\
\hline 2 & Methamidophos & 4.35 & 16.657 & 98 \\
\hline 3 & Dichlorvos & 6.43 & 18.582 & 109 \\
\hline 4 & Carbofuran & 7.27 & 12.680 & 164 \\
\hline 5 & Methiocarb & 10.02 & 22.092 & 168 \\
\hline 6 & Propachlor & 10.69 & 19.734 & 120 \\
\hline 7 & Cyhalothrin & 11.76 & 8.282 & 198 \\
\hline 8 & Atrazine & 12.24 & 17.538 & 200 \\
\hline 9 & Acetochlor & 13.57 & 17.217 & 59 \\
\hline 10 & Chlorpyrifos & 14.54 & 17.066 & 97 \\
\hline 11 & $\alpha$-Endosulfan & 16.17 & 14.907 & 241 \\
\hline 12 & $\mathrm{p}, \mathrm{p}^{\prime}-\mathrm{DDE}$ & 16.55 & 25.480 & 246 \\
\hline 13 & Dieldrin & 16.69 & 23.834 & 79 \\
\hline 14 & $\beta$-Endosulfan & 17.30 & 15.254 & 195 \\
\hline 15 & $o, p^{\prime}-\mathrm{DDD}$ & 17.36 & 44.900 & 235 \\
\hline 16 & o, p'-DDT & 18.06 & 3.041 & 235 \\
\hline 17 & Acetamiprid & 18.82 & 24.242 & 56 \\
\hline 18 & Pyridaben & 20.92 & 17.945 & 147 \\
\hline 19 & Cypermethrin-1 & 21.74 & 46.252 & 181 \\
\hline 20 & Fenvalerate-1 & 22.60 & 11.544 & 125 \\
\hline 21 & Fenvalerate-2 & 22.85 & 10.172 & 125 \\
\hline 22 & Difenoconazole-1 & 23.19 & 10.856 & 265 \\
\hline 23 & Difenoconazole-2 & 23.27 & 10.622 & 265 \\
\hline
\end{tabular}


shaken for $1 \mathrm{~h}$ at $200 \mathrm{rpm}$ through shaker, then the mixture was poured into separating funnel and the layers were let to separate. The upper organic layer was collected in a round bottom flask, and lower aqueous layer was again treated with $60 \mathrm{~mL}$ of ethyl acetate. The mixture was shaken for $15 \mathrm{~min}$. Then the organic layer was separated and mixed with the previously collected layer. Organic layer was dried with sodium sulphate anhydrous. The solution was filtered and evaporated to dry residue through rotary evaporator. The dried residue was reconstituted in $2 \mu \mathrm{L}$ of dichloromethane. The solution was filtered through $0.45 \mu \mathrm{mL}$ membrane filter and injected $2 \mu \mathrm{L}$ into the GC column using auto injection system.

Chromatographic separation of pesticides. A gas chromatograph from Shimadzu hyphenated to a mass spectrometer QP 2010 plus (Tokyo, Japan) equipped with an auto-sampler (AOC-20S) and auto-injector (AOC-20i) was used. Ultra high pure helium was used as carrier gas. All chromatographic separations were performed on a capillary column (DB-5ms; Agilent Technologies, USA) having specifications: length; $30 \mathrm{~m}$, i.d.; $0.25 \mathrm{~mm}$, thickness; $0.250 \mu \mathrm{m}$. Other GC-MS conditions were: ion source temperature (EI); $280{ }^{\circ} \mathrm{C}$, interface temperature; $280{ }^{\circ} \mathrm{C}$, solvent cut time; 2 min. $2 \mu \mathrm{L}$ of samples and standard were injected into the GC column. Injector was operated in a splitless mode. Injection temperature was $250^{\circ} \mathrm{C}$. The column temperature program started at $50^{\circ} \mathrm{C}$ for $1 \mathrm{~min}$ and ramped to $125^{\circ} \mathrm{C}$ at the rate of $25^{\circ} \mathrm{C} / \mathrm{min}$. The temperature was further increased to $220^{\circ} \mathrm{C}$ at the rate of $10^{\circ} \mathrm{C} / \mathrm{min}$ and hold for $15 \mathrm{~min}$. Total elution time was $37.5 \mathrm{~min}$. MS was operated in single ion monitoring (SIM) mode. GC-MS solutions software provided by the supplier was used to control the system and to acquire the data. Identification and quantification of the compounds was carried out by comparing the mass spectra obtained with those of external pesticide mixed standard solution. Qualification of the peaks was further authenticated through standard mass spectra from the NIST library (NIST 05).

\section{Results and Discussion}

Optimisation of the GC-MS conditions. Multi residues method is essential in the case where nothing is known about the possible contamination. Ideally such method should provide less time consuming, with appropriate base line separation giving quantification of as many pesticides as possible in a single run. The pesticides selected were belonging to different classes of pesticides having different polarity and different thermal properties. For obtaining base line chromatographic separation for such mixture, gradient elution is necessary to obtain precise and accurate quantification at residual level. After optimising the GC conditions using different temperature gradient system, resolution of analytes at the base line was achieved. Column selected was DB-5ms which is mostly used for such analyses. Figure 1 shows the GC chromatogram obtained after analysing the 23 pesticides standards mixture. Detail of the retention times, concentrations and quantifying ion ( $\mathrm{m} / \mathrm{z}$ value) of each pesticide is tabulated in Table 1 .

Pesticide residues in drinking water samples. Standard maximum permissible values for pesticide residues in drinking water have been shown in Table 2. Table 3 shows the concentration of pesticides at the level of parts per million (ppm) in the samples collected from Akora Khattak. Aldicarb was detected only in sample AK 1 while in rest it was not detected. Chlorpyrifos was found only in sample no.6 (AK6) while $\beta$-endosulfan was detected only in sample no. 3 (AK3). Residues of carbofuran, cyhalothrin, atrazine, acetochlor, $\alpha$ - endosulfan and dieldrin were not detected in

Table 2. Standard maximum permissible values for pesticide residues in drinking water

\begin{tabular}{|c|c|c|c|}
\hline $\begin{array}{l}\text { Sample } \\
\text { no. }\end{array}$ & Pesticide name & $\begin{array}{l}\text { Max. } \\
\text { permissible } \\
\text { limits } \\
(\mathrm{ppm})\end{array}$ & Reference \\
\hline 1 & Aldicarb & 0.01 & $\begin{array}{l}\text { (Hamilton et al., 2003; } \\
\text { Jenkins, 1999) }\end{array}$ \\
\hline 2 & Methamidophos & - & (Hamilton et al., 2003) \\
\hline 3 & Dichlorvos & 0.012 & (Moermond et al., 2008) \\
\hline 4 & Carbofuran & 0.007 & (Hamilton et al., 2003) \\
\hline 5 & Methiocarb & 0.035 & (Jenkins, 1999) \\
\hline 6 & Propachlor & 0.09 & (Jenkins, 1999) \\
\hline 7 & Cyhalothrin & - & - \\
\hline 8 & Atrazine & 0.002 & (Hamilton et al., 2003) \\
\hline 9 & Acetochlor & 0.14 & ((Jenkins, 1999) \\
\hline 10 & Chlorpyrifos & - & - \\
\hline 11 & $\alpha$ - Endosulfan & 0.042 & (Jenkins, 1999) \\
\hline 12 & $\mathrm{p}, \mathrm{p}^{\prime}-\mathrm{DDE}$ & 0.002 & (Hamilton et al., 2003) \\
\hline 13 & Dieldrin & 0.0002 & (Hamilton et al., 2003) \\
\hline 14 & $\beta$-Endosulfan & 0.042 & (Jenkins, 1999) \\
\hline 15 & o, p'-DDD & 0.002 & (Hamilton et al., 2003) \\
\hline 16 & o, p'-DDT & 0.002 & (Hamilton et al., 2003) \\
\hline 17 & Acetamiprid & - & - \\
\hline 18 & Pyridaben & 0.0001 & (Moermond et al., 2008) \\
\hline 19 & Cypermethrin-1 & - & - \\
\hline 20 & Fenvalerate-1 & - & - \\
\hline 21 & Fenvalerate- 2 & - & - \\
\hline 22 & Difenoconazole-1 & & - \\
\hline 23 & Difenoconazole-2 & - & - \\
\hline
\end{tabular}




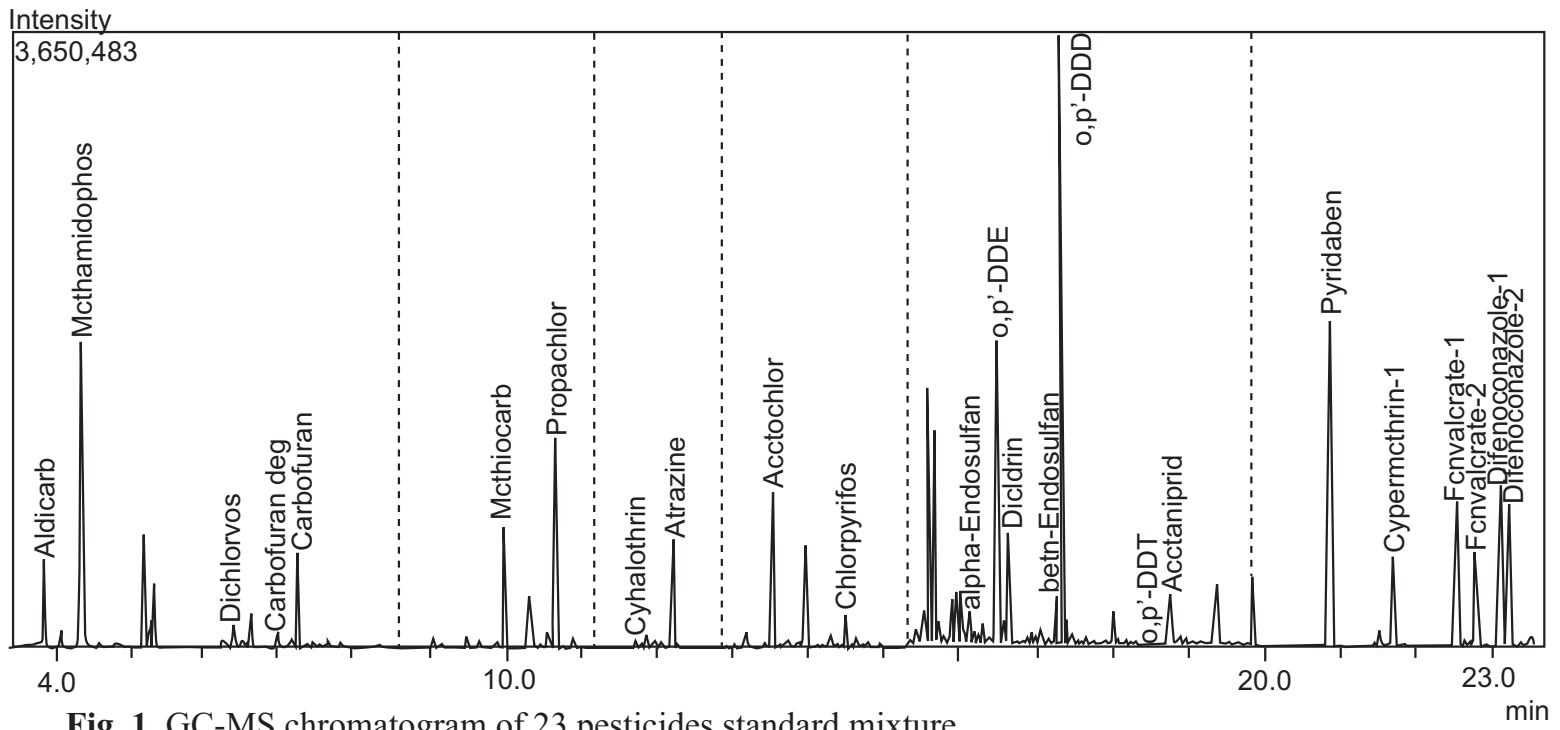

Fig. 1. GC-MS chromatogram of 23 pesticides standard mixture.

Table 3. Quantity (ppm) of pesticides in drinking water samples collected from Akora Khattak (AK) district Nowshera

\begin{tabular}{llllllllll}
\hline \hline $\begin{array}{l}\text { Sample } \\
\text { no. }\end{array}$ & Pesticide name & AK1 & AK2 & AK3 & AK4 & AK5 & AK6 & AK7 & AK8 \\
\hline 1 & Aldicarb & 0.002 & ND & ND & ND & ND & ND & ND & ND \\
2 & Methamidophos & 0.003 & 0.006 & 0.007 & 0.026 & 0.010 & 0.001 & ND & 0.007 \\
3 & Dichlorvos & 0.001 & 0.001 & 0.003 & ND & 0.002 & ND & 0.001 & ND \\
4 & Methiocarb & 0.011 & ND & 0.029 & 0.038 & 0.012 & 0.011 & ND & 0.003 \\
5 & Propachlor & ND & $<0.001$ & $<0.001$ & ND & 0.001 & $<0.001$ & 0.001 & 0.002 \\
6 & Chlorpyrifos & ND & ND & ND & ND & ND & 0.040 & ND & ND \\
7 & p, p'-DDE & $<0.001$ & ND & $<0.001$ & ND & $<0.001$ & ND & 0.001 & 0.005 \\
8 & 3-Endosulfan & ND & ND & 0.001 & ND & ND & ND & ND & ND \\
9 & o,p'-DDD & $<0.001$ & $<0.001$ & 0.001 & $<0.001$ & $<0.001$ & $<0.001$ & 0.001 & 0.003 \\
10 & o, p'-DDT & ND & 0.001 & ND & 0.002 & 0.001 & 0.001 & ND & 0.001 \\
11 & Acetamiprid & $<0.001$ & ND & 0.010 & ND & 0.002 & ND & ND & ND \\
12 & Pyridaben & $<0.001$ & ND & ND & $<0.001$ & $<0.001$ & ND & ND & ND \\
13 & Cypermethrin-1 & ND & ND & $<0.001$ & 0.001 & 0.001 & ND & ND & ND \\
14 & Fenvalerate-1 & ND & ND & $<0.001$ & ND & $<0.001$ & ND & $<0.001$ & 0.004 \\
15 & Fenvalerate-2 & ND & $<0.001$ & 0.002 & $<0.001$ & 0.001 & ND & ND & ND \\
16 & Difenoconazole-1 & ND & ND & $<0.001$ & $<0.001$ & $<0.001$ & $<0.001$ & $<0.001$ & ND \\
17 & Difenoconazole-2 & ND & $<0.001$ & $<0.001$ & ND & ND & ND & ND & ND \\
\hline \hline
\end{tabular}

Table 4a. Quantity (ppm) of pesticides in drinking water samples collected from district Buner (B)

\begin{tabular}{llllllllllll}
\hline \hline $\begin{array}{l}\text { Sample } \\
\text { no. }\end{array}$ & Pesticide name & B1 & B2 & B3 & B4 & B5 & B6 & B7 & B8 & B9 & B10 \\
\hline 2 & Methamidophos & 0.018 & 0.011 & 0.008 & 0.002 & 0.001 & $<0.001$ & 0.002 & 0.002 & 0.014 & 0.001 \\
3 & Dichlorvos & ND & $<0.001$ & ND & 0.001 & ND & ND & $<0.001$ & ND & ND & ND \\
6 & Methiocarb & ND & ND & ND & ND & 0.006 & ND & ND & ND & ND & 0.004 \\
7 & Propachlor & 0.001 & 0.001 & $<0.001$ & $<0.001$ & ND & $<0.001$ & $<0.001$ & $<0.001$ & $<0.001$ & ND \\
11 & Chlorpyrifos & ND & ND & ND & ND & ND & ND & ND & ND & ND & ND \\
13 & p,p'-DDE & $<0.001$ & 0.001 & $<0.001$ & $<0.001$ & $<0.001$ & $<0.001$ & $<0.001$ & $<0.001$ & $<0.001$ & ND \\
16 & o, p'-DDD & $<0.001$ & 0.001 & 0.001 & 0.001 & $<0.001$ & 0.001 & 0.001 & $<0.001$ & ND & $<0.001$ \\
17 & o, p'-DDT & ND & ND & ND & ND & ND & ND & 0.001 & ND & ND & ND \\
18 & Acetamiprid & 0.001 & 0.001 & $<0.001$ & $<0.001$ & ND & ND & ND & ND & ND & ND \\
19 & Pyridaben & ND & $<0.001$ & $<0.001$ & $<0.001$ & $<0.001$ & ND & $<0.001$ & ND & ND & ND \\
\hline \hline
\end{tabular}

$\mathrm{ND}=$ not detected 
Table 4b. Quantity (ppm) of pesticides in drinking water samples collected from district Buner (B)

\begin{tabular}{lllllllll}
\hline \hline $\begin{array}{l}\text { Sample } \\
\text { no. }\end{array}$ & Pesticide name & B11 & B12 & B13 & B14 & B15 & B16 & B17 \\
\hline 2 & Methamidophos & 0.002 & 0.002 & $<0.001$ & 0.004 & 0.007 & 0.002 & 0.039 \\
3 & Dichlorvos & ND & 0.001 & ND & ND & ND & ND & ND \\
6 & Methiocarb & 0.007 & 0.010 & 0.001 & 0.007 & 0.008 & 0.012 & 0.034 \\
7 & Propachlor & ND & $<0.001$ & ND & ND & ND & $<0.001$ & ND \\
11 & Chlorpyrifos & 0.002 & ND & ND & ND & ND & ND & ND \\
13 & p, p'-DDE & $<0.001$ & $<0.001$ & ND & 0.001 & $<0.001$ & $<0.001$ & 0.002 \\
16 & o, p'-DDD & $<0.001$ & $<0.001$ & $<0.001$ & 0.001 & 0.001 & 0.001 & 0.004 \\
17 & o, p'-DDT & ND & ND & ND & $<0.001$ & ND & 0.001 & ND \\
18 & Acetamiprid & ND & 0.001 & ND & $<0.001$ & ND & ND & 0.009 \\
19 & Pyridaben & $<0.001$ & ND & ND & ND & ND & ND & ND \\
\hline \hline
\end{tabular}

$\mathrm{ND}=$ not detected

any of the water samples collected from Akora Khattak. Chlorpyrifos was found in high amounts i.e. $0.040 \mathrm{ppm}$, in AK6 while methamidophos and methiocarb were found in appreciable quantities i.e. $0.026 \mathrm{ppm}$ and $0.038 \mathrm{ppm}$, respectively, in sample no. 4 (AK4). Concentrations of most of the pesticides under study were found at the level below $0.001 \mathrm{ppm}$. Methiocarb concentration $(0.038 \mathrm{ppm})$ was found beyond the permissible limit $(0.035 \mathrm{ppm})$ in AK4. Amounts of the residues of $\mathrm{p}, \mathrm{p}^{\prime}-\mathrm{DDE}$ obtained in sample no. 8 (AK8) (0.005 ppm) and of o, p'-DDD in AK8 (0.003) were above the allowed limit $(0.002 \mathrm{ppm})$. Quantified amount o, p'-DDT in AK4 found at the permissible limit $(0.002 \mathrm{ppm})$. Concentrations of rest of the pesticides residues detected were within the range.

Results obtained from the GC-MS analyses of samples collected from Buner are shown in Table $4 \mathrm{a}$ and $4 \mathrm{~b}$. Aldicarb, carbofuran, cyhalothrin, atrazine, acetochlor, $\alpha$-endosulfan, dieldrin, $\beta$-endosulfan, cypermethrin- 1 , fenvalerate and difenoconazole were not detected in the water samples collected from Buner. Chlorpyrifos was detected only in sample no. 11 (B11) (0.002 ppm). Methamidophos and methiocarb were found in appreciable amounts i.e. 0.039 ppm and 0.034 ppm, respectively, in sample no. 17 (B17). Rest of the pesticides detected and quantified were below $0.010 \mathrm{ppm}$. Concentration of methiocarb found $(0.034 \mathrm{ppm})$ is about to the maximum limit ( $0.035 \mathrm{ppm})$ while that of $\mathrm{p}$, $\mathrm{p}^{\prime}-\mathrm{DDE}$ is at the maximum allowed limit $(0.002 \mathrm{ppm})$ in sample B17 and amount of o, $\mathrm{p}^{\prime}$-DDD $(0.004 \mathrm{ppm})$ quantified in B17 is beyond the limit $(0.002 \mathrm{ppm})$. Concentrations of rest of the pesticides residues detected in water samples from Buner were within the permissible limits. From the results it appears that drinking waters sources in the area under study have been contaminated with pesticides which is a health hazard and may be a source of various diseases in these areas.

\section{Conclusion}

From the data collected in this study, it is evident that the flood water has contaminated the drinking water sources especially in the flood hit areas like Akora Khattak. Therefore, proper measures should be taken to clean the drinking water from such contaminants. It is further suggested that preventive actions should be taken to avoid such occurrence in future leading to health problems.

\section{References}

Abhilash, P.C., Singh, N. 2009. Pesticide use and application: an Indian scenario. Journal of Hazardous Materials, 165: 1-12.

Abid, M.H., Qureshi, M.N., Ali, M.J., Ziaurahaman, M. 2010. A Report on the Bacteriological Investigations of Drinking Water of the Flood 2010 Affected Areas of Khyber Pukhtoonkhwa. PCSIR Laboratories Complex Peshawar, Pakistan, pp. 1-18.

Androutsopoulos, V.P., Hernandez, A.F., Liesivuori, J., Tsatsakis, A.M. 2013. A mechanistic overview of health associated effects of low levels of organochlorine and organophosphorous pesticides. Toxicology, 307: 89-94.

Arlien-Soberg, P. 1992. Solvent Neurotoxicity. 373 pp., CRC Press, Boca Raton, FL, USA.

Bassil, K.L., Vakil, C., Sanborn, M., Cole, D.C., Kaur, J.S., Kerr, K.J. 2007. Cancer health effects of pesticides - Systematic review. Canadian Family Physician, 53: 1704-1711.

Brown, S.K., Ames, R.G., Mengle, D.C. 1989. Occupational illness from cholinesterase inhibiting pesticides among agriculture pesticide applicators in California. Archives of Environmental Health, 44: 34-39. 
Chambers, H.W. 1992. Organophosphorus compounds: an overview In: Organophosphates: Chemistry, Fate and Effects, J.E. Chambers, P.E. Levi (eds.), pp. 3-18, Academic Press, San Diego, CA, USA.

Hamilton, D.J., Ambrus, A., Dieterle, R.M., Felsot, A.S., Harris, C.A., Holland, P.T., Katayama, A., Kurihara, N., Linders, J., Unsworth, J. 2003. Regulatory limits for pesticide residues in water. Pure and Applied Chemistry, 75: 1123-1155.

Hayat, K., Ashfaq, M., Ashfaq, U., Saleem, M.A. 2010. Determination of pesticide residues in blood samples of villagers involved in pesticide application at District Vehari (Punjab), Pakistan. African Journal of Environmental Science and Technology, 4: 666-684.

Hernández, A.F., Parrón, T., Tsatsakis, A.M., Requena, M., Alarcón, R., López-Guarnido, O. 2013. Toxic effects of pesticide mixtures at a molecular level: their relevance to human health. Toxicology, 307: 136-145.

AOAC, 2002. Official Methods of Analysis of the Association of Official Analytical Chemists. (AOAC), International, W. Horwitz (ed.), Chapter 10, pp. 97-136, Gaithersburg, Maryland, USA.

Hueser, G. 1992. Diagnostic markers in clinical immunotoxicology and neurotoxicology. Journal of Occupational Medicine and Toxicology, 1: 5-10.

Jenkins, J.J. 1999. Drinking Water Standards and Guidelines for Pesticides Sampled in Oregon Ground and Surface Water. pp. 1-8.

Kanavouras, K., Tzatzarakis, M.N., Mastorodemos, V., Plaitakis, A., Tsatsakis, A.M. 2011. A case report of motor neuron disease in a patient showing significant level of DDTs, HCHs and organophosphate metabolites in hair as well as levels of hexane and toluene in blood. Toxicology and Applied Pharmacology, 256: 399-404.

Karalliedde, L., Senanayake, N. 1999. Organophosphorus insecticide poisoning. Journal of the International
Federation of Clinical Chemistry, 11: 1-9.

Kesavachandran, C.N., Fareed, M., Pathak, M.K., Bihari, V., Mathur, N., Srivastava, A.K. 2009. Adverse health effects of pesticides in agrarian populations of developing countries. Reviews of Environmental Contamination and Toxicology, 200: 33-52.

Luster, M.I., Rosenthal, G.J. 1993. Chemical agents and the immune response. Environmental Health Perspectives, 100: 219-226.

Moermond, C.T.A., Mensink, B.J.W.G., Vos, J.H. 2008. Environmental risk limits for pyridaben. RIVM Letter Report Number 60176021, Bilthoven, The Netherlands.

Moon, H.B., Kim, H.S., Choi, M., Yu, J., Cho, H.G. 2009. Human health risk of polychlorinated biphenyls and organochlorine pesticides resulting from seafood consumption in South Korea, 2005-2007. Food and Chemical Toxicology, 47: 1819-1825.

Palis, F.G., Flor, R.J., Warburton, H., Hossain, M. 2006. Our farmers at risk: behaviour and belief system in pesticide safety. Journal of Public Health, 28: 43-48.

Salameh, P.R., Waked, M., Baldi, I., Brochard, P., Saleh, B.A. 2006. Chronic bronchitis and pesticide exposure: a case-control study in Lebanon. European Journal of Epidemiology, 21: 681-688.

Soomro, A.M., Seehar, G.M., Bhanger, M.I., Channa, N.A. 2008. Pesticides in the blood samples of sprayworkers at agriculture environment. The toxicological evaluation. Pakistan Journal of Analytical and Environmental Chemistry, 9: 32-37.

Vial, T., Nicolas, B., Descotes, J. 1996. Clinical immunotoxicity of pesticides. Journal of Toxicology and Environmental Health, 48: 215-229.

Zaganas, I., Kapetanaki, S., Mastorodemos, V., Kanavouras, K., Colosio, C., Wilks, M.F., Tsatsakis, A.M. 2013. Linking pesticide exposure and dementia: What is the evidence? Toxicology, 307: 3-11. 